\title{
Por que ler os clássicos? \\ A formação da sociedade brasileira e a construção do território no livro Raízes do Brasil de Sérgio Buarque de Holanda
}

\author{
Why read the classics? \\ The formation of the brazilian society and the construction of the territory In the \\ book \\ Raízes do Brasil by Sérgio Buarque de Holanda
}

Leonardo Civale

Geógrafo - Prof ${ }^{\circ} \operatorname{Dr}^{\circ}$ do Departamento de Geografia da

Universidade Federal de Viçosa - UFV/MG, Brasil

civale@ufv.br

\begin{abstract}
Resumo
O livro Raízes do Brasil de Sérgio Buarque de Holanda, publicado em 1936, tem sido objeto de várias Interpretações e Inúmeros trabalhos, sobretudo, na área da historiografia e da sociologia, porém, são raríssimas as referências ao autor por parte daqueles que se dedicam a pensar e a fazer história da geografia ou geografia histórica. $\mathrm{O}$ artigo pretende compreender as categorias de análise operadas por Sérgio Buarque de Holanda em sua sIngular Interpretação sobre a formação da sociedade e do território brasileiros e refletir o valor heurístico dessas categorias de análise para a geografia humana contemporânea. Não há a menor dúvida que o livro Raízes do Brasil privilegia uma Interpretação diacrônica sobre a formação do território e da sociedade brasileira. No entanto, uma questão emInentemente geográfica perpassa praticamente todos os capítulos: a adaptação de uma cultura adventícia a um meio geográfico que lhe era estranho. $\mathrm{O}$ artigo argumenta que a Interpretação de Sérgio Buarque de Holanda além de beber na mesma fonte da geografia francesa e da geografia americana - o pensamento neokantiano - ganha em dimensão ao se basear nos fundamentos do modernismo brasileiro e sua Interpretação sobre a sIngularidade cultural do Brasil. Visto por este prisma, o artigo defende que a noção de meio da geografia francesa de Vidal de La Blache, de paisagem cultural da geografia americana de Carl Sauer e a sIngularidade cultural proposta pelo modernismo brasileiro dialogam entre si no livro de Sérgio Buarque de Holanda, destacando o espaço como o resultado do encontro de diferentes matrizes culturais. Tal circunstância, por si só, já garantiria a longevidade do livro, no entanto, ao argumentar que os lugares foram gerados por dInâmicas históricas sIngulares e irredutíveis à modernidade ocidental, Sérgio Buarque mostra a sofisticação teórica do pensamento social brasileiro dos anos 1930.
\end{abstract}

Palavras-chave: Pensamento Geográfico, Geografia Histórica, Formação Territorial Brasileira.

\begin{abstract}
The book roots of Brazil by Sérgio Buarque de Holanda, published In 1936, has been the subject of various Interpretations and numerous works, especially In the field of historiography and sociology, however, are very few references to the author from those who dedicate themselves to thInk and make history of geography or historical geography. The article Intends to understand the categories of analysis operated by Sérgio Buarque de Holanda In his sIngular Interpretation on the formation of the company and of the Brazilian territory and reflect the heuristic value of these categories of analysis for human geography. There is no doubt that the book roots of Brazil favors a diachronic Interpretation about the formation of the territory and the brazilian society. However, an issue emInently pervades virtually every geographic chapters: the adaptation of a adventitious to culture a
\end{abstract}


geographical environment that was weird. The article argues that the Interpretation of Sergio Buarque de Holanda Besides drInkIng In the same font of French geography and geography-the neo-Kantian thought-WINS In dimension to be based In the foundations of Brazilian modernism and their Interpretation on the cultural uniqueness of Brazil. Seen In this light, the article argues that the notion of Middle French geography of Vidal de La Blache, cultural landscape of American geography by Carl Sauer and cultural sIngularity proposed by Brazilian modernism dialogue among themselves In the book of Sérgio Buarque de Holanda, highlightIng the space as the result of the encounter of different cultural matrices. Such circumstance In itself would guarantee the longevity of the book, however, to argue that the places were generated by sIngular and irreducible historical dynamics to Western modernity, Sérgio Buarque shows the theoretical sophistication of Brazilian social thought of the years 1930 .

Keywords: Geographic Thought, Historical Geography, Brazilian Territory Formation.

\section{INTRODUÇÃO}

Os homens que estão hoje um pouco para cá ou um pouco para lá dos cInquenta anos aprenderam a refletir e a se Interessar pelo Brasil, sobretudo em termos de passado em função de três livros: "Casa Grande e Senzala”, de Gilberto Freyre, publicado quando estávamos no gInásio; "Raízes do Brasil”, de Sérgio Buarque de Holanda, publicado quando estávamos no curso complementar; "Formação do Brasil Contemporâneo", de Caio Prado Júnior quando estávamos na escola superior ${ }^{l}$.

A afirmação contida no prefácio do livro Raízes do Brasil de Sérgio Buarque de Holanda, na edição de 1967, feita por Antônio Cândido não se restrInge apenas à geração cuja maturidade Intelectual viria a ocorrer, entre os anos 30 e 40 do século XX, portanto, no período de formação do Estado nacional moderno no Brasil. A Influência desses livros na formação da elite Intelectual do país, certamente, alcançou e provocou a reflexão em gerações posteriores ${ }^{2}$.

Não obstante a afirmação de Antônio Cândido ter um caráter consagrador, por si só, ela não teria o condão de transformar Casa Grande e Senzala, Raízes do Brasil e Formação do Brasil Contemporâneo em clássicos das ciências sociais no Brasil e, seus autores, em "pais fundadores" do pensamento social brasileiro contemporâneo. Para se compreender a repercussão dos livros e dos autores há que se levar em consideração não apenas a análise histórica da formação da sociedade e do território brasileiro baseada em uma sólida perspectiva teórica e metodológica, mas, sobretudo, a origInalidade das obras, no que diz respeito à Interpretação da sIngularidade nacional. Casa Grande e Senzala de Gilberto Freyre, Raízes do Brasil de Sérgio Buarque de Holanda e Formação do Brasil Contemporâneo de Caio Prado Júnior contêm riquíssimas lições sobre a sIngularidade da sociedade brasileira e da formação do território nacional.

\footnotetext{
${ }^{1}$ CÂNDIDO, Antônio. O Significado de Raízes do Brasil. Prefácio do Livro. In: HOLANDA, Sérgio Buarque de. Raízes do Brasil. $25^{\text {a }}$ edição, Rio de Janeiro: José Olympio, 1993.

${ }^{2}$ Ibidem.
} 
Não há dúvida que o prefácio de Antônio Cândido contribuiu de maneira significativa para a consagração desses três livros como clássicos do moderno pensamento social brasileiro e, seus respectivos autores, como "pais fundadores" das ciências sociais no Brasil. No entanto, a trajetória do livro Raízes do Brasil, nos quase trInta anos que se seguiram, desde sua publicação até o prefácio do professor Antônio Cândido, revelava a consistência dos argumentos e a solidez da análise geográfica e historiográfica do seu autor.

Desde então o livro de Sérgio Buarque de Holanda tem sido objeto de várias Interpretações e Inúmeros trabalhos, sobretudo, na área da historiografia e da sociologia. Porém, são raríssimas as referências ao autor por parte daqueles que se dedicam a pensar e a fazer história da geografia. Tal fato não deixa de causar certa estranheza dado o caráter fortemente geográfico do livro, sobretudo naquilo que diz respeito à formação do território brasileiro, da relação entre rural e urbano e da construção das suas primeiras cidades.

O presente artigo não tem a pretensão de reivIndicar uma IInhagem nobre para a geografia no Brasil, nem tampouco, “descobrir", "resgatar" ou "dar visibilidade” à teorias ou metodologias perdidas na poeira da história. $\mathrm{O}$ artigo tem a pretensão, por outro lado, de compreender as categorias de análise operadas por Sérgio Buarque de Holanda, no contexto histórico de sua sIngular Interpretação sobre a formação da sociedade e do território brasileiros, bem como, refletir sobre o valor heurístico dessas categorias de análise para a geografia humana contemporânea.

Não há a menor dúvida que o livro Raízes do Brasil de Sérgio Buarque de Holanda privilegia, evidentemente, a Interpretação diacrônica da formação do território e da sociedade. No entanto, uma questão emInentemente geográfica perpassa praticamente todos os capítulos: a adaptação de uma cultura adventícia a um meio geográfico que lhe era estranho.

$\mathrm{O}$ artigo argumenta, portanto, que a Interpretação de Sérgio Buarque de Holanda em Raízes do Brasil bebe na mesma fonte que a geografia francesa das três primeiras décadas do século XX. Certamente, a mesma matriz teórica que nutria a geografia produzida por Carl Sauer nos Estados Unidos nos anos 1920 desse mesmo século: o pensamento neokantiano.

Além disso, o artigo reivIndica uma filiação de Sérgio Buarque de Holanda ao universo cultural do modernismo brasileiro dos anos de 1920, pois, se havia uma identidade entre os Intelectuais do período, esta se caracterizava pelo desejo de ver sepultado o belletrismo oitocentista e pela realização do sonho do progresso. Para os Intelectuais do período havia uma necessidade urgente de se construir uma identidade que sIngularizasse o país no concerto das nações. As questões levantadas pelo livro Raízes do Brasil de Sérgio Buarque de Holanda só podem ser compreendidas dentro do contexto em que este foi elaborado e publicado.

$\mathrm{O}$ artigo defende que, as noções de meio e de paisagem geográfica, construída pela geografia francesa do Início do século XX e, a ideia de paisagem cultural, cultivada pela geografia 
americana do mesmo período, não seriam apenas apropriadas pela ampla erudição, como também dialogariam perfeitamente com a Interpretação da sIngularidade cultural do Brasil, proposta pelos autores do modernismo brasileiro.

Como um produto cultural do seu tempo, o livro Raízes do Brasil deve ser Interpretado dentro do contexto em que foi elaborado, mas também, deve ser compreendido de acordo com as leituras do autor. Em outras palavras o livro é um produto em si e uma Interpretação marcada pelo seu tempo. Contudo, não seria considerado um clássico das ciências sociais no Brasil se não houvesse nele algo que garantisse a sua atualidade. Assim, se levarmos em consideração algumas propostas da geografia humana contemporânea ${ }^{3}$ nas quais o espaço, o lugar ou o território devem ser Interpretados como sendo o resultado do encontro entre diferentes matrizes históricas e culturais, o livro Raízes do Brasil, ou melhor, a perspectiva teórica em que o livro foi escrito, aInda poderia servir como uma contribuição importante para a geografia humana.

\section{O MÉTODO É A QUESTÃO: UM POSSÍVEL CAMINHO PARA A COMPREENSÃO DA CONSTRUÇÃO DO OLHAR DE SERGIO BUARQUE DE HOLANDA}

Este artigo tem por objetivo revisitar o livro, Raízes do Brasil de Sérgio Buarque de Holanda e seguir, em trajetória retrospectiva, o camInho do autor até a sua publicação. O livro Raízes do Brasil foi publicado em 1936 e, pelo menos em sua maior parte, escrito nos últimos anos da década de 20 do século XX, quando o autor estava na Europa como correspondente de um jornal paulistano. Não deveria causar nenhuma estranheza, se levarmos em consideração a erudição e a seriedade do autor, a quantidade de Inclusões, exclusões, alterações, correções, bem como, as exaustivas revisões, a que o texto foi submetido até a versão publicada em 1936.

O livro em si já é um documento histórico e constrói uma forma de se Interpretar a sIngularidade do Brasil. Como em toda obra de Interpretação histórica e sociológica, o livro de Sérgio Buarque fazia um camInho até as origens à guisa de entendimento dos problemas do país no momento em que o texto estava sendo escrito. $O$ retorno às origens estava orientado, evidentemente, por questões contemporâneas. A questão central era o problema da identidade nacional. Trazida à tona pelos modernistas dos anos 20 do século $\mathrm{XX}$, dentre os quais o próprio autor, esta se transformaria, na década seguInte, no Santo Graal dos Intelectuais brasileiros que chegavam à maturidade em plena Era Vargas.

\footnotetext{
${ }^{3}$ MASSEY, Doreen B. Pelo Espaço: uma nova política da espacialidade. Tradução Hilda Pareto Maciel, Rogério Haesbaert. Rio de Janeiro: Bertrand Brasil, 2009.
} 
Segundo Michel de Certeau ${ }^{4}$ o discurso histórico explicitaria uma identidade social, não como algo "dado", mas, como este é capaz de se diferenciar de uma época anterior, a escrita da história teria sempre o privilégio de fundar uma origem. AInda segundo Certeau, a escrita da história assumira, entre as modernas sociedades, o lugar dos primitivos mitos, já que era através destes que as sociedades antigas e tradicionais representavam as relações ambíguas com as suas origens.

O texto de Certeau tem para o presente artigo uma importância semInal porque serve literalmente para ilumInar o camInho e orientar a aproximação da trajetória de Sérgio Buarque de Holanda desde a militância nas fileiras modernistas até a publicação do livro Raízes do Brasil, em 1936. A abordagem que Certeau faz da escrita da história enquanto um saber sobre as origens serviu para a orientação e defInição da metodologia de trabalho. Se, como diz Certeau, o discurso histórico funda uma origem, mas ao mesmo tempo, se diferencia dela, a análise do livro de Sérgio Buarque requeria duas formas de Interpretação. A primeira dizia respeito à sIncronia, ou seja, era necessário situar o trabalho de Sergio Buarque horizontalmente, dentro do contexto histórico dos anos 30 do século XX. Neste caso, o famoso prefácio, da edição de 1967, de Antônio Cândido respondia ao primeiro desafio metodológico, posto que, o texto do crítico literário situava o livro como um dos pilares da tríade de Intérpretes do Brasil a época, junto com Casa Grande e Senzala de Gilberto Freyre e Formação do Brasil Contemporâneo de Caio Prado Junior.

O outro eixo da metodologia é diacrônico e, certamente, um pouco mais complexo. O livro de Sérgio Buarque Investiga as origens históricas da sociedade brasileira e da sua formação territorial à procura de respostas para questões que aInda estariam vivas na sociedade brasileira do período, o Brasil da década de 1930. Entretanto, o livro Raízes do Brasil, aInda que mobilizasse teorias e metodologias Inovadoras, certamente poderia ser considerado tributário de uma corrente do pensamento social brasileiro que remontava, pelo menos até a década de 70 do século XIX. Seu autor é Inquestionavelmente, um dos herdeiros do patrimônio Intelectual do pensamento social brasileiro produzido nos estertores do Império e nas fileiras da Primeira República. Se vista com a lógica da contInuidade, essa caudalosa corrente jamais deixou de se debruçar sobre a identidade nacional e, não por acaso, talvez tenha atIngido seus momentos de maior relevância justamente nos fInais do regime monárquico e na crise da década de 20 do século XX que culmInaria na Revolução de 30 .

A decantada geração de 1870, que Incluía nomes como Joaquim Nabuco, Alberto Salles, Sílvio Romero, Lopes Trovão, Tobias Barreto, entre outros tantos, faria da questão da identidade nacional profissão de fé. Não é por acaso que essa geração elegeu a identidade nacional como uma de suas prIncipais preocupações, uma vez que estes autores foram contemporâneos da crise que

\footnotetext{
${ }^{4}$ CERTEAU, Michel de. A escrita da história. Tradução Maria de Lourdes Menezes. Rio de janeiro: Forense Universitária, 1982. p.55-56.
} 
sepultaria, de uma vez por todas, o Império dos Bragança. A questão da identidade nacional estava diretamente relacionada ao lugar do Brasil entre as nações civilizadas do planeta e isso significava encarar o problema da escravidão.

A geração dos modernistas, cujo manifesto simbólico seria a icônica Semana de Arte Moderna de 1922, da qual Sérgio Buarque faria parte, não era menos brilhante e, aInda que os problemas não fossem os mesmos, a questão da identidade nacional era absolutamente Incontornável. Uma geração que revelaria Intelectuais como Mario de Andrade, Oswald de Andrade, Manuel Bandeira, Menotti del Picchia, Villa Lobos e outros tantos, elegeria como missão a ruptura com o passado de fantasias românticas e assumiria a construção de um olhar sIngular sobre um país tropical de população mestiça.

Aqui, pela necessidade de um esclarecimento metodológico, caberia chamar a atenção da vInculação de Sérgio Buarque de Holanda. Certamente, um erudito como o autor deve ser visto tanto quanto um tributário da corrente do pensamento social brasileiro que vInha atuando desde o século XIX, como também, um dos expoentes dos modernistas das primeiras décadas do século XX. Sérgio Buarque chegaria à maturidade em plena crise da Primeira República que se estenderia por toda a década de 20 do século XX e termInaria com ascensão de Getúlio Vargas ao poder. Os anos 30 do século XX presenciariam um esforço gigantesco de se compreender a sIngularidade do Brasil.

Embora estejamos nos referIndo a dois momentos históricos distIntos, no que concerne à crise política, os Intelectuais de cada período viveriam situações semelhantes: a necessidade de se identificar as forças em conflito e a oportunidade de se construir não apenas uma nova identidade, mas um novo paradigma para se pensar o país. Todos aqueles que se dedicaram a Investigar o pensamento social brasileiro perceberam que é justamente nos períodos de crise em que há um recrudescimento da procura por identidade. Esta, por sua vez, teria o condão de despertar as Instituições que se encarregam da memória, bem como, aqueles que procuram Interpretar as memórias sociais adormecidas. Não é obra do destIno, portanto, que em época de crise do regime o tema da identidade voltaria sempre à baila. A cada ruptura Institucional parecia ser necessário um retorno às origens para se compreender o prIncípio de todos os males.

Hoje, cada vez mais aparecem trabalhos sobre a obra de Sérgio Buarque de Holanda. Alguns trabalhos se debruçam sobre sua trajetória como historiador e outros sobre os prIncipais temas de sua historiografia. No entanto, aInda recentemente os trabalhos sobre Sérgio Buarque enfocavam a corrente do pensamento social brasileiro da qual o autor era um dos atores prIncipais.

Apenas no último quarto de século apareceram trabalhos dos mais importantes historiadores brasileiros que Incluíram a obra de Sérgio Buarque como uma das mais fundamentais no pensamento social brasileiro. Desde a obra da historiadora Ângela de Castro Gomes, História $e$ 
Historiadores $^{5}$, publicada no ano de 1999 até o mais recente livro organizado por LIncoln Secco e Luiz Bernardo Pericás, Intérpretes do Brasil. Clássicos, rebeldes e renegados ${ }^{6}$, que apareceu em 2014; passando pelo trabalho de Francisco Iglésias, Historiadores do Brasil: capítulos de historiografia brasileira ${ }^{7}$, publicado em 2000 e As identidades do Brasil. De Varnhagen a FHC ${ }^{8}$, de José Carlos Reis, publicado em 2008.

Não é novidade na história do pensamento geográfico ou na história da geografia trabalhos sobre a construção da sociedade brasileira e sua formação territorial. Trabalhos que se debruçaram sobre essa temática existem desde a defInição da geografia enquanto saber acadêmico no Brasil. Não custa lembrar que Caio Prado Junior autor do livro, hoje clássico, Formação do Brasil Contemporâneo 9 foi um dos fundadores da Associação de Geógrafos Brasileiros. Na realidade, se levarmos em consideração a tradição da própria geografia os artigos remontam às primeiras décadas do século XX ou até mesmo ao século XIX, se levarmos em conta aquilo que Antônio Carlos Robert de Moraes denomIna de ideologias geográficas ${ }^{10}$. Passando, evidentemente, pelos trabalhos contemporâneos de Manuel Correia de Andrade $^{11}$ e, um pouco mais recente, os artigos do próprio Antônio Carlos Robert de Moraes e Lia Osório Machado ${ }^{12}$.

O presente artigo, aInda que tenha como Interesse prIncipal Investigar a trajetória política e Intelectual de Sérgio Buarque de Holanda e a maneira como o autor foi forjando a subjetividade e polIndo a sua capacidade de Interpretação, se Inscreve nesta tradição da historiografia e da história do pensamento geográfico.

\footnotetext{
${ }^{5}$ GOMES, Ângela de Castro. História e historiadores. Rio de Janeiro: FGV, 1999.

${ }^{6}$ PERICÁS, Luiz Bernardo e SECCO, Lincoln. Intérpretes do Brasil. Clássicos, rebeldes e renegados. São Paulo: Boitempo, 2014.

${ }^{7}$ IGLÉSIAS, Francisco. Historiadores do Brasil: capítulos de historiografia brasileira. Rio de Janeiro: Nova Fronteira; Belo Horizonte: UFMG, 2000.

${ }^{8}$ REIS, José Carlos. As Identidades do Brasil. De Varnhagen a FCH. Rio de Janeiro: FGV, 2008.

${ }^{9}$ PRADO, Caio. Formação do Brasil Contemporâneo. São Paulo. Companhia das Letras, 2011.

${ }^{10}$ MORAES, Antônio Carlos Robert. Ideologias Geográficas: espaço, cultura e política no Brasil. São Paulo: Annablume, 1988.

${ }^{11}$ ANDRADE, Manuel Correia. Formação Territorial e Econômica do Brasil. Recife: Fundação Joaquim Nabuco/ Editora Massangana, 2006.

${ }^{12}$ MACHADO, Lia Osório. Origens do Pensamento Geográfico no Brasil: meio tropical, espaços vazios e a ideia de ordem (1870-1930).In: CASTRO, Iná Elias. GOMES, Paulo César Costa. CORRÊA, Roberto Lobato. Geografia: Conceitos e Temas. Rio de Janeiro, Bertrand Brasil, 1995.
} 


\section{RAÍZES DO BRASIL: UM OLHAR DIFERENTE SOBRE O BRASIL}

Dentro de uma perspectiva diacrônica, podemos perceber que o livro Raízes do Brasil segue o mesmo camInho anteriormente desbravado pelo pioneirismo de Capistrano de Abreu nos seus livros Capítulos de História Colonial e CamInhos Antigos e Povoamento do Brasil ${ }^{13}$. Dentro dessa perspectiva, ambos os livros procuram desvendar os primórdios da formação territorial e do povoamento Brasil, bem como, destacam como foco prIncipal, a Investigação sobre a identidade nacional brasileira ${ }^{14}$. Entretanto, se o livro de Capistrano pode ser lido como uma Interpretação positivista da formação territorial brasileira, o livro de Sérgio Buarque de Holanda Inaugura uma abordagem culturalista, sustentada por uma análise baseada em pares antagônicos. SIngular no que diz respeito à história da formação do território e da sociedade no Brasil, à medida que, Interpreta os fatos históricos não como realidades em si, mas como o resultado da ação de uma expressão cultural adventícia em um ambiente onde tudo estava por desbravar, conquistar, civilizar. O livro de Sérgio Buarque de Holanda, por outro lado, rompe com a perspectiva diacrônica e Inaugura outra maneira de Interpretar a formação da sociedade e do território. Em Raízes do Brasil, Sérgio Buarque de Holanda não se deixa guiar apenas pelos fatos, antes Interpreta a formação da sociedade e do território brasileiro a partir de uma leitura política e cultural que privilegia a transposição e adaptação de uma determInada subcultura europeia a um ambiente tropical.

Levando em consideração uma perspectiva sIncrônica, o livro revela o diálogo do autor com o que havia de mais elaborado no pensamento social europeu e norte-americano entre os anos 20 e 30 do século XX. A abrangência teórica do autor abarca desde autores da sociologia da cultura alemã à historiografia francesa, passando por autores da geografia humana e da antropologia cultural americana.

$\mathrm{O}$ artigo, portanto, analisa o livro partIndo de dois eixos prIncipais: o diacrônico e o sIncrônico. Assim, o leitor vai encontrar uma análise do contexto histórico e sociocultural em que o livro foi escrito, bem como, uma tentativa de compreender o mundo das ideias, ou seja, as estruturas do pensamento e o mundo conceitual de Sérgio Buarque de Holanda. Ideias estas que, uma vez mobilizadas pelo autor, Inauguraram uma abordagem Interpretativa. Uma forma de Interpretar que revelaria a sIngularidade da sociedade brasileira e a importância fundamental do território na história do Brasil.

No livro, Sérgio Buarque traça a genealogia do processo de domInação e construção do território a partir do encontro, aInda que violento, de uma cultura estrangeira com as diversas

\footnotetext{
${ }^{13}$ ABREU, Capistrano de. Capítulos de História Colonial: 1500-1800. Brasília: Conselho Editorial do Senado Federal, 1998.\&Caminhos Antigos e Povoamento do Brasil. Belo Horizonte: Itatiaia; São Paulo: Editora da Universidade de São Paulo, 1988.

${ }^{14}$ REIS, José Carlos. Op. cit.
} 
culturas locais. Se apoiando na hermenêutica e na sociologia da cultura de expressão alemã, herdeira do neokantismo, o autor constrói um conceito de "homem cordial"15 que seria a representação social da transposição da civilização portuguesa para essa borda do Atlântico. Em Raízes do Brasil, o espaço geográfico não se resume ao palco em que a civilização lusitana representaria todos os seus dramas históricos. O espaço geográfico aparece como o resultado da adaptação dessa mesma civilização a uma terra que em si era quase totalmente desconhecida. A noção de espaço geográfico como resultado da relação entre a sociedade e a natureza, capital para a geografia, perpassa todos os capítulos do livro de Sérgio Buarque de Holanda. Para o autor o espaço era, Inescapavelmente, o resultado da ação de uma determInada cultura sobre o ambiente local e, tal ação resultaria, Inevitavelmente, em um espaço geográfico sIngular. O resultado da conquista portuguesa, de terras que viriam a ser o Brasil, seria a construção de uma expressão cultural única em cenário tropical. A partir desse encontro, a paisagem natural deixaria de ser apenas natural e seria Incorporada em uma visão edênica; o espaço não seria apenas aquilo que deveria ser conhecido, mas o território que viria ser conquistado; o povo não teria um traço único, mas sim, mais seria o fruto Inescapável da mestiçagem. Por isso, Sérgio Buarque faria uso dos pares antagônicos. Para ele a sIngularidade da sociedade brasileira não se explicaria apenas pela transposição de uma cultura estrangeira, mas antes pela Incorporação de hábitos e costumes das culturais locais por uma cultura adventícia. A história e a geografia dariam lugar a uma realidade cultural absolutamente sIngular.

\section{O MOVIMENTO MODERNISTA E O ENCONTRO COM O PAÍS REAL}

Levando em consideração o contexto em que o livro foi escrito e as discussões em voga naquele momento, os anos 20 e 30 do século XX, no Brasil, podemos destacar como as prIncipais contribuições do autor: a análise da formação histórica da identidade nacional, o processo de modernização da sociedade brasileira e o estudo da formação de uma classe dirigente, Inquestionavelmente, ligada à questão territorial. No entanto, uma leitura mais focada na parte conceitual do livro revela também importantes contribuições teóricas e metodológicas para o pensamento social contemporâneo e para a Geografia Humana: a relevância do contexto histórico para a compreensão do fenômeno social, o papel da identidade local em momentos de crise e

\footnotetext{
${ }^{15}$ Em uma extensa nota de número 157 da $25^{\text {a }}$ edição do livro Raízes do Brasil, Sérgio Buarque de Holanda credita a expressão "homem cordial" ao escritor Ribeiro Couto. Ainda nessa nota, Sérgio Buarque, a propósito de uma interpretação equivocada de Cassiano Ricardo, explica que a expressão homem cordial foi, por ele utilizada, no sentido exato e estritamente etimológico. Para Sérgio Buarque a expressão "homem cordial" identificaria um tipo ideal e, se referia ao homem que age com o coração, não devendo, portanto, ser confundida com bondade, hospitalidade ou generosidade. A nota se faz necessária, pois o autor teve que explicar o uso da expressão durante toda a vida.
} 
redefInição da nacionalidade e a necessidade de mobilizarmos diferentes Instrumentais teóricos na abordagem histórica e geográfica.

Curiosamente, justamente em um momento de efervescência política e cultural posterior à Semana de 22 e à Revolução de 30, quando, na ordem do dia, aparecia a rediscussão da identidade nacional, todos os conhecimentos históricos produzidos, bem como, toda a contribuição teórica e metodológica, mobilizados pelo autor ficariam em segundo plano. Todas as reflexões do autor sucumbiriam ante ao impacto causado pelo conceito de tipo ideal de matriz weberiana do "homem cordial". Sérgio Buarque haveria de passar o resto de sua vida tendo que explicar que o qualificativo "cordial" vInha de uma ação baseada no coração e não na razão e, portanto, não poderia ser Interpretada como sInônimo de bondade ou cordialidade.

As últimas três décadas do século XIX e as três primeiras do século XX assistiram a uma profunda transformação política e econômica na sociedade brasileira. Coube, portanto, aos Intelectuais, de então, produzir uma série de Interpretações e propostas, fosse como um diagnóstico dos nossos males de origem fosse como terapêutica visando à solução desses mesmos males. Muitos escreviam tendo a expectativa de produzir um duplo movimento: identificar os problemas nacionais e, ao mesmo tempo, propor as soluções modernizadoras. As Interpretações sobre a realidade nacional se debruçavam, sobretudo, sobre as possibilidades de desenvolvimento a despeito daquilo que eram considerados os grandes desafios do pensamento social brasileiro: uma população mestiça, o clima tropical e o tamanho do território.

As questões suscitadas pela sIngularidade nacional permaneceriam Indeléveis tanto para a elite pensante do Império decadente quanto para aqueles Intelectuais formados nos bancos escolares da República Velha. No entanto, entre estas duas gerações de Intelectuais brasileiros, não há como desconsiderar o impacto causado pela I Guerra Mundial e a explosão de ideias liberadas aInda sob o rastro da tragédia. Os Intelectuais europeus e, consequentemente, os Intelectuais brasileiros, visto que estes sempre estiveram em perfeita sIntonia com os acontecimentos e a reflexão da outra margem do Atlântico, se entregaram à missão de vasculhar a tradição Intelectual ocidental e separar o joio do trigo. A guerra provocaria uma profunda transformação tanto no pensamento europeu, quanto nos Intelectuais brasileiros. Ela poderia ser considerada um ponto de Inflexão para a Intelectualidade do período. Os Intelectuais europeus, Inconformados com o presente e desiludidos quanto ao futuro da civilização ocidental, a partir de então, desprezavam as ideias do século XIX acreditando que elas seriam, aInda que apenas em parte, responsáveis pelo conflito generalizado e a carnificIna dos campos de batalha. Alternativas teóricas, novas formas de expressão artística, variadas experimentações políticas, sociais e culturais eram buscadas dentro e fora do contexto europeu. 
Por outro lado, aqueles que estavam na outra margem do ocidente europeu, portanto, do lado de cá do Atlântico, mas que bebiam em suas fontes, não deixaram de refletir sobre a alteridade de sua própria condição. A guerra provocara uma espécie de terremoto Intelectual fazendo submergir todo um modelo de civilização e, ao mesmo tempo, fazendo surgir Incontáveis experiências Intelectuais e, dando a oportunidade daquilo que estava à margem do pensamento ocidental, migrar para o centro. As teorias que buscavam explicar as diferenças entre os homens baseada nos conceito de clima, meio e raça, bastante em voga entre o fInal do século XIX e Início do século XX, seriam atiradas por terra ${ }^{16}$. No seu lugar as teorias econômicas liberais e marxistas e as teorias culturalistas de diversos matizes adquiriam um grande valor heurístico. No Brasil dos anos 20 e 30 do século $\mathrm{XX}$, os autores que se autodenomInavam de modernos, e podemos situar Sérgio Buarque entre eles, cansados do formalismo belletrista e dos paradigmas científicos gestados no século XIX se mostraram atentos às alternativas propostas pela modernidade europeia. Sérgio Buarque deve, portanto, ser lido como um desses Intelectuais do período que se debruçaram sobre a tarefa de reconstrução do pensamento ocidental e que encarava o desafio de passar o país a limpo.

O movimento modernista brasileiro, apesar de nascer do diálogo com as vanguardas europeias procurava estabelecer paradigmas e padrões de identidade tipicamente nacionais. Certamente, as relações dos modernistas com as vanguardas europeias, sobretudo o movimento surrealista, Influenciou a ruptura com padrões etnocêntricos europeus, mas, além disso, esse diálogo acirrou a procura de uma identidade nacional. A tal identidade nacional era uma maneira de se assumir diante do processo de universalização. Para participar do concerto das nações era necessário se pronunciar a partir das diferenças nacionais fundamentais. Anos mais tarde o projeto modernista Inverteria, portanto, a perspectiva do pensamento social brasileiro dos oitocentos e, abandonaria o idealismo dos autores românticos pela perspectiva de construção de uma verdadeira subjetividade nacional.

Se as questões sobre os obstáculos que impediam o país de camInhar rumo ao desenvolvimento permaneciam imutáveis e eram recorrentes desde as três últimas décadas do século XIX, as respostas, no entanto, se mostrariam distIntas. As ideias modernistas permitiam aos Intelectuais do período se debruçar sobre aquela que seria a questão crucial: compreender a sIngularidade do país antes aos desafios universais do progresso. Desse modo, o clima tropical, antes visto como um obstáculo à adaptação de homens brancos à terra, nesse momento passaria a ser encarado como a metáfora da exuberância; o gigantismo do território, antes visto como um desafio à Integração, diante da cobiça de outros povos, seria visto como um potencial de riqueza e desenvolvimento, bem como, um celeiro de subculturas regionais prontas a serem difundidas por

\footnotetext{
${ }^{16}$ SCWARCZ, Lilia. História do Brasil Nação: 1808-2010. Rio de Janeiro: Objetiva, 2012. Vol.3. “A Abertura para o mundo: 1889-1930”. P. 20.
} 
todo país; a mestiçagem, anteriormente Interpretada como uma espécie de condenação, seria reescrita positivamente e adquiriria um traço marcante e irredutível do caráter do país.

Se existia algum traço em comum entre os Intelectuais do período, este traço era o desejo de superação dos obstáculos e o alcance do Incontornável sonho do progresso. O desejo de se construir um programa de transformação das estruturas arcaicas da realidade brasileira. Havia, entretanto, uma necessidade de se defInir uma identidade que sIngularizasse o país no concerto das nações, pois seria Incongruente com os padrões de modernidade, vigentes, ser moderno e não ter uma identidade. O camInho do progresso no paradigma ocidental passava necessariamente pela Investigação da sIngularidade. Era a senha para que todos se debruçassem sobre a realidade histórica do país, portanto, as questões suscitadas pelo livro de Sérgio Buarque de Holanda se explicam, em parte, pelo contexto histórico em que este foi escrito. Neste sentido, o livro de Sérgio Buarque, Raízes do Brasil seria mesmo emblemático, pois, representaria um verdadeiro mergulho naquilo que seriam as raízes dos problemas brasileiros. Não seria, portanto, obra do acaso nem o título do livro, nem tampouco, a questão prIncipal: uma Investigação sobre as raízes históricas da sIngularidade brasileira.

\section{PARA ALÉM DO "HOMEM CORDIAL"}

O livro Raízes do Brasil foi escrito entre o fInal dos anos vInte e o Início dos anos trInta e publicado, pela primeira vez, em 1936. Para o autor, o Brasil era fruto de uma herança da colonização lusitana mesclada aos hábitos e costumes localistas. No livro Sérgio Buarque mergulha fundo no processo histórico de formação da cultura nacional e, desse caldo de cultura, se construiria aquilo que, aInda que sob a forma de conceito, seria a contribuição do Brasil para o concerto das nações: o "homem cordial". Desde o seu aparecimento a obra foi Interpretada a partir da chave do "homem cordial" e, de certa maneira, essa Interpretação equivocada orientou todas as leituras posteriores. Contudo, tal Interpretação mInimizava a força da densidade teórica de Sérgio Buarque e sombreava a compreensão da tese contida no livro. O ideal tipo de cunho weberiano construído por Sérgio Buarque com base na formação da sociedade brasileira só tem valor heurístico se for encarado através de sua transitoriedade. Para o autor, o "homem cordial" deveria ser situado no âmbito da sociedade patriarcal colonial, mas, com o processo de modernização a estrutura agrária na qual este se origInou estaria condenada a desaparecer. Portanto, o processo de modernização ao fim e ao cabo transformaria completamente a sociedade brasileira. A construção teórica com base no tipo ideal era tão Inusitada no pensamento social brasileiro que atrairia toda a atenção da crítica especializada. Tal movimento impediu que se percebesse a fortuna metodológica do autor, ou seja, a maneira como a obra foi escrita, deixava claro que o processo de modernização da estrutura agrária 
brasileira em curso desde aquele momento levaria Inevitavelmente ao desaparecimento do "homem cordial". Na realidade, quando do aparecimento da obra, Sérgio Buarque já afirmava que se o "homem cordial" aInda existia, sua morte já havia sido anunciada.

O autor afirmava estar em curso uma revolução lenta e gradual, que, certamente daria à luz a uma nova nação e, essa revolução estaria sendo gestada nos grandes centros urbanos que, progressivamente, cresciam em importância e teriam a força necessária para desalojar as heranças culturais e, com ela, desapareceria, o "homem cordial". Para Sérgio Buarque, essa mudança, entretanto, vInha ocorrendo desde meados do século XIX com o aparecimento e o desenvolvimento em escala comercial da lavoura de café. Segundo o autor, as próprias características desse sistema produtivo implicavam em mudanças acentuadas, sobretudo porque permitiam ao produtor se descolar do espaço produtivo das fazendas e das áreas rurais e partir em direção às cidades.

Sérgio Buarque de Holanda demonstra, ao longo do livro, que uma nova identidade brasileira estava em curso. A transformação não se resumiria apenas à modernização, antes à construção de uma identidade basicamente moderna. O movimento histórico traria à tona um duplo movimento: uma nova identidade, afeita aos padrões modernos e a decadência de quadros antigos, que permaneceriam durante um tempo, mas que, cedo ou tarde desapareceriam por completo.

Sua análise carregava a força de uma perspectiva historicista, onde a racionalidade não pairava acima do mundo dos homens, mas antes emanava da realidade concreta. Para Sérgio Buarque de Holanda, qualquer teoria ou prIncípio político que pairasse acima da realidade constituída, estaria, em sua essência, condenado ao fracasso. Coerente com suas perspectivas libertárias, o autor via a transformação se escondendo no seio da realidade social. Sérgio Buarque condenava os prIncípios importados como modelos impossíveis de organizar a desordem nacional criativa e desejava que a sociedade brasileira encontrasse os prIncípios que estivessem de acordo com a mais íntima essência e o ritmo espontâneo. Certamente, Sérgio Buarque poderia ser vInculado a uma vertente do modernismo: àquela que procurava uma espécie de essência, uma característica verdadeiramente nacional que sIngularizasse o país no concerto das nações. No entanto, a despeito da sua vInculação ao modernismo brasileiro, Sérgio Buarque compreendia a história como um processo e, certamente, não lamentava o desaparecimento do "homem cordial" ante os padrões da modernidade.

\section{A GEOGRAFIA HUMANA NAS RAÍZES DO BRASIL}

A sociedade brasileira nasceu do encontro violento entre o movimento de expansão do ocidente europeu com as populações americanas e a Incorporação compulsória de populações de origem africana. A particularidade dessa formação histórica brasileira, resultado do encontro de 
culturas diversas, suscita importantes questões teóricas e metodológicas para aqueles que se dedicam à Geografia Humana. Entre tantas possíveis questões que podem surgir da leitura atenta do livro Raízes do Brasil para a Geografia contemporânea seria relevante destacar apenas duas: como construir uma Geografia Humana que não reproduza uma concepção IInear e positivista do tempo histórico? Como Interpretar o lugar não apenas como resultado de um processo de expansão de um centro irradiador das Inovações, mas, sobretudo, como produto do encontro de diferentes trajetórias históricas?

O sistema mundo colonial moderno provocou reações diversas durante a longa duração de sua implantação na superfície de quase todo o planeta. Entre estas reações podemos destacar: a busca por uma identidade própria que teria sido subalternizada pela implantação do sistema moderno; a Incorporação quase completa dos valores, hábitos e costumes ocidentais; a hibridização entre os valores domInantes da cultura ocidental com aqueles das populações subalternizadas ${ }^{17}$.

Os diferentes processos históricos locais, entre eles o processo de formação da sociedade e do território brasileiro, permitem perceber que, na realidade, existiram diferentes maneiras de reação ante a construção de um sistema que se irradiava pelo mundo a partir do eixo do mundo europeu ocidental. Durante os últimos três séculos, progressivamente, o sistema mundo moderno se transformava em uma realidade mundial. Portanto, em outras palavras, a modernidade, ou aquilo que ela representava em termos de ideias, mercadorias e projetos políticos, emanava de um determInado polo central, ou seja, o mundo europeu ocidental. Visto por esse ponto de vista, todo o restante do planeta se transformava, Inevitavelmente, em periferia do processo de expansão ocidental.

No livro Raízes do Brasil, Sérgio Buarque deixa claro que a prIncipal característica da sociedade brasileira seria o fato dela ser Inescapavelmente parte do ocidente. O autor, como tantos outros antes e depois dele, compreendia perfeitamente que o Brasil era parte da expansão do mundo ocidental moderno, no entanto, não deixava de destacar, com a agudeza crítica do seu pensamento, a sIngularidade que caracterizava a sociedade brasileira. O livro pode ser lido como a Interpretação histórica de uma sociedade que se construiu nos trópicos, fruto do encontro de culturas locais e adventícias sob o domínio de populações brancas. Nesta chave de leitura a sociedade brasileira seria o fruto de um processo histórico que gerou a periferia do capitalismo moderno. Para esta sociedade, modernidade, universalidade e identidade viriam a ser a mesma coisa. Nascida da fissura entre o ocidente e o não ocidente, para a sociedade brasileira a identidade e a modernidade eram Incontornáveis, justamente porque, o projeto de construção da modernidade estava

${ }^{17}$ HALL, Stuart. A identidade Cultural na Pós-Modernidade. Rio de Janeiro: DP\&A, 2004. 
Inextricavelmente associado à tarefa de superar as peias do atraso através dos paradigmas da modernização.

Entretanto, o livro Raízes do Brasil também pode ser lido como a tentativa de compreender a construção de uma subjetividade brasileira. A Interpretação de Sérgio Buarque não negligencia os mecanismos de construção do sistema mundo, nem tampouco, as alternativas para superá-lo, mas, por outro lado, busca compreender o processo de gestação no Brasil dos conceitos de identidade e modernidade. Tal fato aparentemente evidente ganha em densidade quando se leva em consideração o que se entende por modernidade na sociedade brasileira. A modernidade seja do ponto de vista técnico, seja do ponto de vista político, ou mesmo filosófico sempre foi vista como algo produzido externamente, no mundo europeu ou norte-americano. A modernidade sempre foi um paradigma para os Intelectuais brasileiros. Esta era um modelo a ser alcançado a partir do momento em que os obstáculos do atraso fossem defInitivamente removidos ou um modelo a ser discutido visando à adaptação aos trópicos.

Em Raízes do Brasil, Sérgio Buarque mobilizou poderosas ferramentas teóricas e conceituais se utilizando ao mesmo tempo da hermenêutica e da sociologia da cultura alemã para mostrar a possibilidade de se compreender a particularidade nacional sem que se precisasse abrir mão das categorias de análise universais. $\mathrm{O}$ texto do livro pode ser lido, portanto, como um produto do encontro da história do rigor conceitual com a necessidade modernista de Interpretar o passado da nação. Para Sérgio Buarque a aparente desordem que imperava nestas plagas tInha, por outro lado, a pureza e a vitalidade das origens e isso explicava a dificuldade do brasileiro em se dobrar ante ao poder coercitivo da civilização. Não seria obra do acaso, portanto, a utilização do conceito de tipo ideal de matriz weberiana para entender a vitalidade de homem brasileiro, nem tampouco a lógica compreensiva da hermenêutica histórica para situar esse homem brasileiro no contexto histórico, social e cultural que lhe deu origem.

A modernidade foi um período histórico marcado por grandes experiências humanas: experiências políticas, sociais e Intelectuais. Por um lado, tais experiências foram responsáveis pelo nascimento das ciências históricas como Instrumento fundamental para os homens compreenderem o desenvolvimento das sociedades. Por outro lado, as revoluções burguesas do fInal do século XVIII geraram a noção de progresso. Os pensadores do século XIX, herdeiros diretos das profundas transformações e variadas experiências levadas adiante pelos atores da Revolução Francesa, fizeram o trabalho de síntese entre a história como Instrumento de compreensão do desenvolvimento das sociedades e a ideia de progresso. O fabuloso resultado desse trabalho Intelectual foi, desde então, o entendimento da história como o local privilegiado onde o povo construiria a sua própria liberdade. A história seria, portanto, pensada, a partir do século XIX como a ideia de progresso e seu prIncipal 
motor o desejo de liberdade ${ }^{18}$. Tal processo explica o motivo de, até hoje, haver uma relação profunda entre história e a ideia de progresso.

Para as ciências humanas surgidas na segunda metade do século XIX, compreender a história era uma tarefa fundamental, pois ela representava a possibilidade de decodificar a realidade e, ao mesmo tempo, permitia captar o movimento das sociedades. A história era também uma espécie de genealogia e compreendê-la era como ter a posse de uma sabedoria capaz de decifrar a forma como a sociedade se desenvolvia ao longo do tempo e organizava seu espaço. Compreender o fluxo da história era, portanto, construir uma identidade social, pois significava ser capaz de Interpretar do fenômeno nacional. Compreender o passado permitiria ao Investigador um duplo movimento: ser capaz de perceber as contInuidades presentes e, portanto, construir os projetos para o futuro. A história se transformava, então, na chave do progresso. Chave esta que permitiria um duplo movimento: entender o passado e construir o futuro.

A ciência história como legítima representante da liberdade humana, seria, em realidade, uma verdadeira tecnologia política. A história era vista como o lugar da liberdade do espírito humano e como ideia de progresso e fazia da escala do tempo, a escada para o desenvolvimento da civilização. Tal concepção, por um lado, reforçou o caráter modernizador da história, porém, por outro lado, gerou a ideia de um centro irradiador do processo de modernização. Escrever a história a partir desse centro serviu Inevitavelmente para tornar secundárias as sIngularidades locais.

Na realidade, Raízes do Brasil, na medida em que se refere ao processo de modernização da sociedade como uma espécie de sepultura do "homem cordial", paga o seu tributo à história como ideia de progresso. O autor pensava a história como ideia de progresso e, estava convicto de que o país era uma extensão da cultura ocidental, mas o seu comprometimento com os ideais modernistas ressaltam a ideia de sIngularidade local. Trata-se, portanto, de um livro que pode contribuir imensamente para o debate dos atuais rumos da Geografia, pois se nele está explícito que a sociedade brasileira é o resultado da transposição de uma cultura adventícia para um espaço novo, também está claro que essa cultura adventícia não lograria êxito se não se utilizasse do equipamento cultural local.

\section{CONSIDERAÇÕES FINAIS}

Uma análise focada nas ideias que permitiram a Interpretação de Raízes do Brasil permite destacar algumas contribuições teóricas fundamentais para a Geografia Histórica: a necessidade de se considerar o contexto histórico em que os fenômenos foram produzidos e os problemas que

\footnotetext{
${ }^{18}$ ARENDT, Hannah. Entre o Passado e o Futuro. São Paulo, Perspectiva, 1972.
} 
estavam postos para os produtores Intelectuais do período, a importância, aInda que como pano de fundo, da construção do território na explicação da história do Brasil e a necessidade de mobilizar diferentes Instrumentais teóricos para explicar a sIngularidade da construção dos lugares e a dInâmica de sua transformação Interna. O livro ensIna também que é fundamental compreender os processos que deram origem aos fenômenos sociais e a formação territorial.

No entanto, a lição mais importante do livro, passados exatamente oitenta anos de sua primeira edição, é a ideia da Incontornável sIngularidade dos espaços humanizados. Em outras palavras, o espaço humano deve ser Interpretado como o resultado do encontro de diferentes histórias, aInda que quase sempre, a construção desse espaço humano venha sendo, quase Inevitavelmente, de uma violência extrema. Os conceitos de "Homem Cordial" e "Semeador e Ladrilhador", de matriz weberiana, de certa maneira, representam essa perspectiva metodológica. Essa é a abordagem privilegiada por Sérgio Buarque quando se refere à sociedade brasileira como o resultado da adaptação de um grupo adventício em um cenário tropical. Seria obra do acaso que quase toda a produção historiográfica de Sérgio Buarque posterior à Raízes do Brasil se concentraria não apenas em mapear, mas, em compreender a penetração do homem branco pelo Interior do país, sobretudo, a partir do planalto paulista? Sua Interpretação estava concentrada na realidade local, no entanto, o autor não a isolava de um sistema mundo que, progressivamente, estava sendo construído nos dois últimos séculos. Para Sérgio Buarque, era Inquestionável a circunstância histórica de o país ser o resultado da expansão europeia para o ocidente, no entanto, a Incorporação como periferia de um centro irradiador da modernidade deveria ser estudada a partir das realidades locais.

A grande erudição adquirida ao longo uma vida dedicada às letras propiciou a Sérgio Buarque um verdadeiro arsenal teórico e metodológico na busca de compreender a sIngularidade da sociedade brasileira. Por um lado, o autor fez jus ao universo teórico e conceitual da moderna historiografia, ao explicar o processo histórico de adaptação de populações adventícias ao mundo tropical através da contraposição de pares antagônicos como "atraso" e "modernização", "reação" e "progresso" e "local" e "global". Por outro lado, o autor se apropriou do saber da geografia humana do período para explicar as formas como o ambiente natural brasileiro foi sendo transformado pelo processo de ocupação, dando origem ao "homem cordial". Em outras palavras, a erudição de Sérgio Buarque permitiu que o autor se apropriasse de uma ampla gama de saberes teóricos que abarcava os campos disciplInares, hoje divididos, da história, da geografia humana e das ciências sociais e, dessa forma, utilizasse o conhecimento para Interpretar a irredutibilidade da experiência histórica e do lugar geográfico da sociedade brasileira.

Como dissemos antes, longe de ser uma espécie de reivIndicação de filiação nobre para a moderna reflexão da geografia histórica no Brasil, este artigo teve por objetivo refletir sobre a 
história e a geografia dos lugares de uma maneira complexa e Integrada. Encarar a história como ideia de progresso é aceitar, aInda que de forma implícita, que ela necessariamente, deve ter um núcleo central e daí ser irradiada para os outros lugares. A história como ideia de progresso tem um sentido e, este sentido, conduz Inevitavelmente, como uma saga épica, à narrativa dos "povos europeus com história" em direção aos lugares dos "povos sem história" e, portanto, sem narrativa. Esse modelo, na realidade, não se reduz apenas a uma simples abordagem, este modelo reforça o sentido da colonização e a subalternização dos "povos sem história".

Portanto, uma alternativa possível seria Interpretar, não apenas os diferentes lugares do planeta, mas, sobretudo, as diferenças dos lugares do planeta. Pensar os lugares, como tradicionalmente foi feito não é necessariamente a mesma coisa que pensar as diferenças entre os lugares, pois, Investigar os lugares como o resultado de um processo histórico único é diferente de Interpretar os lugares como o resultado do encontro de processos históricos distIntos. Embora possa parecer um jogo de IInguagem apenas, se trata, na realidade, de uma mudança de perspectiva. Compreender os lugares como um fenômeno gerado por um processo histórico único tem o seu valor heurístico, no entanto, essa perspectiva não deve negligenciar os processos históricos distIntos que geraram os lugares distIntos.

Doreen Massey ${ }^{19}$ argumenta em seu livro que os lugares foram gerados por dInâmicas históricas sIngulares e irredutíveis à modernidade ocidental. Interpretar os lugares como o resultado de dInâmicas históricas distIntas permite perceber os diferentes lugares, mas também, as múltiplas faces adquiridas pela modernidade que, produzida em um núcleo central, adequou, transformou, ou destruiu realidades locais. A geografia humana poderia, portanto, oferecer sua contribuição ao se debruçar sobre as sIngularidades dos lugares não como o resultado de uma história única, mas como lugares diferentes construídos por histórias distIntas. Tal abordagem garantiria aos lugares a centralidade de verdadeiras esquInas do tempo e ponto de Interseção de diferentes histórias. Por fim, esse procedimento ajudaria a construir um paradigma de Interpretação dos lugares baseado nas diferentes histórias. Um ponto de partida que não reproduzisse de maneira Ingênua e pouco reflexiva os modelos de uma história tradicional positivista. Quem sabe, se a escrita da terra se transformasse em um verdadeiro Inventário das diferenças não seria mais simples compreender o sentido de desterrados na própria terra como afirmava Sérgio Buarque há exatos oitenta anos no livro Raízes do Brasil. 


\section{REFERÊNCIAS}

ABREU, Capistrano de. Capítulos de História Colonial: 1500-1800. Brasília: Conselho Editorial do Senado Federal, 1998.

ABREU, Capistrano de. CamInhos Antigos e Povoamento do Brasil. Belo Horizonte: Itatiaia; São Paulo: Editora da Universidade de São Paulo, 1988.

ANDRADE, Manuel Correia. Formação Territorial e Econômica do Brasil. Recife: Fundação Joaquim Nabuco/ Editora Massangana, 2006.

ARENDT, Hannah. Entre o Passado e o Futuro. São Paulo, Perspectiva, 1972.

CÂNDIDO, Antônio. Literatura e Sociedade. São Paulo, Cia Editora Nacional, 1985.

CASTRO, Iná Elias. GOMES, Paulo César Costa. CORRÊA, Roberto Lobato. Geografia: Conceitos e Temas. Rio de Janeiro: Bertrand Brasil, 1995.

CERTEAU, Michel de. A escrita da história. Tradução Maria de Lourdes Menezes. Rio de janeiro: Forense Universitária, 1982.

CORREAA, Roberto Lobato. Geografia: Conceitos e Temas. Rio de Janeiro, Bertrand Brasil, 1995.

CORRÊA, Roberto Lobato. As Ideias no lugar: O Desenvolvimento do Pensamento Geográfico no Brasil no Início do Século XX. Terra Brasilis: Geografia e Pensamento Social Brasileiro, julho/dezembro, São Paulo, 2000.

COSGROVE, Denis. A geografia está em todo lugar: cultura e simbolismo na geografia humana. In: CORRÊA, Roberto Lobato e ZENY, Rosendahl. Paisagem, tempo e cultura. Rio de Janeiro: Eduerj, 2004, $2^{\mathrm{a}}$ edição. CORRÊAA, R.L. (orgs.).

GOMES, Ângela de Castro. História e historiadores. Rio de Janeiro: FGV, 1999.

HALL, Stuart. A identidade Cultural na Pós-Modernidade. Rio de Janeiro: DP\&A, 2004.

HARVEY, David. A condição pós-moderna. Tradução: Ubirajara Sobral e Maria Stela Gonçalves. São Paulo: Edições Loyola, 1992.

HOLANDA, Sérgio Buarque. Raízes do Brasil. Rio de Janeiro, Editora José Olympio, 1967.

IGLÉSIAS, Francisco. Historiadores do Brasil: capítulos de historiografia brasileira. Rio deJaneiro: Nova Fronteira; Belo Horizonte: UFMG, 2000.

LIMA, Nísia TrIndade. Um Sertão Chamado Brasil: Intelectuais e representação geográfica da identidade nacional. Rio de Janeiro, Revan, 1999.

MASSEY, Doreen B. Pelo Espaço: uma nova política da espacialidade. Rio de Janeiro, Bertrand do Brasil, 2009.

MORAES, Antônio Carlos Robert. Notas sobre Identidade Regional e Institucionalização Geográfica no Brasil. Estudos Históricos, vol 4 n 8, pp 149-280, 1991. 
MORAES, Antônio Carlos Robert. Ideologias Geográficas. São Paulo, Editora Hucitec, 1996.

MORAES, Antônio Carlos Robert. Território e História no Brasil. São Paulo, Annablume, 2005.

ORTIZ, Renato. Cultura Brasileira e Identidade Nacional. São Paulo, Brasiliense, 2003.

PERICÁS, Luiz Bernardo e SECCO, LIncoln. Intérpretes do Brasil. Clássicos, rebeldes e renegados. São Paulo: Boitempo, 2014.

PRADO Jr., Caio. Formação do Brasil Contemporâneo. São Paulo. Companhia das Letras, 2011.

REIS, José Carlos. As Identidades do Brasil: de Varnhagen a FHC. $4^{\text {a }}$ Edição, Rio de Janeiro: editora FGV, 2001.

SOUZA, C.V. A Pátria Geográfica: sertão e litoral no pensamento social brasileiro.Goiânia, Editora da UFG, 1997.

SCHWARCZ, Lilia. História do Brasil Nação: 1808-2010. Rio de Janeiro: Objetiva, 2012. Vol.3. A Abertura para o mundo: 1889-1930. 